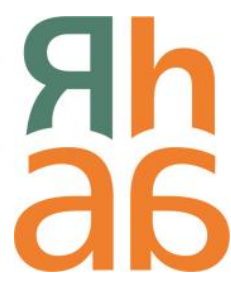

\title{
"Por este muero hoy": Suicidio, acción comunicativa y representación de la identidad femenina en la Ciudad de Buenos Aires (1859-1888)
}

\section{“Today I die for him": Suicide, communicative action and representation of female identity in the City of Buenos Aires (1859-1888)}

\author{
Julián Arroyo \\ Universidad Nacional del Centro de la Provincia de Buenos Aires \\ Facultad de Ciencias Humanas \\ Centro de Estudios Sociales de América Latina / \\ Consejo Nacional de Investigaciones Científicas y Técnicas \\ Tandil, Buenos Aires, Argentina \\ iD https://orcid.org/0000-0003-2023-4050 \\ julianarroyo86@gmail.com
}

\section{Resumen}

En el presente artículo abordamos, desde una perspectiva histórica sociocultural, un conjunto de casos de suicidio ocurridos en la ciudad de Buenos Aires entre 1859 y 1888, con el fin de observar el contenido de los mensajes escritos por las mujeres que se quitaron la vida y su relación con el horizonte femenino de expectativas de la época. Al mismo tiempo, al indagar estos referentes empíricos también prestamos especial atención a dos cuestiones. En primer lugar, los distintos tipos de enunciados transmitidos en las notas (declarativos, expresivos, regulativos, etc.).

Cómo citar este artículo/ How to cite this article: Arroyo, J. (2021). "Por este muero hoy": Suicidio, acción comunicativa y representación de la identidad femenina en la Ciudad de Buenos Aires (18591888). Revista de Historia Americana y Argentina, 56 (2), pp. pp 47-76. https://doi.org/10.48162/rev.44.011 
Asimismo, si la suicida se hacía responsable de lo sucedido, o, bien, si culpaba, directa o indirectamente, a otros de sus actos.

Palabras clave: suicidio; muerte; Buenos Aires; historia cultural; siglo XIX.

\begin{abstract}
In this article we study, from a historical and sociocultural perspective, a set of suicide cases that occurred in the city of Buenos Aires between 1859 and 1888 to analyze the letters left by women who committed suicide, and its relationship with the feminine horizon of expectations. Also, one of our specific objectives is to explore the different types of statements transmitted in the notes (declarative, expressive, regulative, etc.). At the same time, we investigated whether the suicide assumed responsibility for her actions or blamed others for what happened.
\end{abstract}

Key words: suicide; death; Buenos Aires; 19th century; cultural history.

Recibido: 19/10/2020. Aceptado: 05/02/2021

\title{
Introducción
}

En este trabajo buscamos realizar un aporte al estudio histórico y cultural de las representaciones y prácticas relacionadas con los suicidios, en línea con las investigaciones sobre la muerte desde las ciencias sociales ${ }^{1}$. Para ello consultamos un conjunto de hechos sucedidos en la ciudad de Buenos Aires, en el último tercio del siglo XIX. Durante este período, de forma paralela al crecimiento demográfico y las transformaciones en el espacio urbano, surgieron un conjunto de problemáticas que los miembros de las elites buscaron comprender y prevenir: por ejemplo, las enfermedades, el delito, la propagación de los vicios y los comportamientos inmorales (como el juego o la prostitución), las patologías mentales o los actos suicidas. De este modo, los estudios demográficos, el higienismo, la psiquiatría alienista, la medicina legal y la criminología, desde diferentes perspectivas, se ocuparon de estudiar los suicidios en Buenos Aires. Estos, como se ha

\footnotetext{
${ }^{1}$ En este trabajo retomamos ideas abordadas en el noveno capítulo de la Tesis Doctoral del autor, así como nuevas fuentes documentales, reflexiones y argumentos desarrollados a partir de nuestras tareas de investigación actuales. Agradezco al Consejo Nacional de Investigaciones Científicas y Técnicas (CONICET), por brindarme el financiamiento necesario para llevar adelante mis estudios de postgrado y, en la actualidad, por proveer los fondos para la etapa postdoctoral.
} 
explicado en trabajos previos, fueron identificados como un fenómeno social (Otero, 1991; 2004) ${ }^{2}$. Desde esta mirada, el incremento de los casos de muerte por mano propia era una consecuencia de las transformaciones de la vida moderna y civilizada.

Para estudiar las representaciones y prácticas vinculadas con los suicidios en este contexto, analizamos los testimonios registrados en los sumarios judiciales de la época. Para desarrollar nuestra investigación hemos consultado los sumarios judiciales del fondo Tribunal Criminal de la ciudad de Buenos Aires, disponibles en el Archivo General de la Nación (en adelante, AGN, FTC). Estos abarcan el período que va de 1859 a 1888 . De este modo, relevamos 722 expedientes, en los que figuran un total de 724 casos de suicidio (500 consumados y 224 tentativas). Parte de este material fue consultado por Donna Guy (2014) para estudiar los casos de suicidio de las prostitutas de la ciudad de Buenos Aires, entre 1880 y 1900 . Asimismo, también hemos revisado algunos ejemplares de los diarios La Prensa y La Nación, a fin de observar los discursos que circulaban en los medios gráficos acerca de los casos de suicidio. En la documentación hallamos diferentes formas de representar al sujeto que llevaba adelante el acto suicida ${ }^{3}$. Había relatos en los que se trataba de un individuo desesperado por cuestiones materiales o por conflictos familiares; en otros, los suicidas tenían sus "facultades mentales alteradas" por distintos tipos de enfermedades mentales ${ }^{4}$. Asimismo, a partir de la lectura de los sumarios seleccionados, pudimos identificar diferentes tipos narrativos. Así,

\footnotetext{
${ }^{2}$ Marcelo Otero (1991 y 2004) estudió el discurso médico sobre el suicidio en el ámbito intelectual porteño de entre siglos. Otero utilizó la producción científica de la época para mostrar que ideas similares a las de Durkheim (2004 [1897]) estaban siendo gestadas en Buenos Aires, antes de la llegada de El Suicidio a la Argentina. Como señala el autor, desde principios de la década de 1880, los profesionales de la salud analizaban el fenómeno como un problema social, consecuencia de la vida en el mundo urbano y moderno.

${ }^{3}$ En línea con los estudios sociales y culturales de la suicidiología, pensamos los suicidios como sucesos cargados de significado individual, aunque también colectivo. Véase, entre otros, Hjelmeland (2010), Fitzpatrick (2011) y Owens et al (2012). Sobre el suicidio desde una perspectiva sociocultural véase también: Vitenti (2016). El concepto de representación utilizado en nuestra investigación fue elaborado a partir de las ideas expuestas por Henri Lefebvre (2006).

${ }^{4}$ Hemos encontrado pocas investigaciones que aporten a la comprensión del suicidio desde una perspectiva histórica en Argentina, por ejemplo: Otero (1991), Guy (2014), Arroyo (2018, 2020a, 2020b) y González (2019).
} 
encontramos distintas tramas que se repetían con mayor frecuencia, a la hora de relatar los actos suicidas ocurridos en la capital del estado argentino, entre 1859 y 1888. De este modo, identificamos las historias verosímiles enunciadas por el suicida y los integrantes de su red vincular. Al mismo tiempo pudimos indagar los valores y creencias que daban sentido a un suicidio, es decir, los principios del marco axiológico ${ }^{5}$. En la etapa más reciente de nuestra investigación, por otro lado, optamos por poner el foco en las acciones comunicativas de los que se quitaron la vida. En este sentido, uno de nuestros objetivos es analizar el papel que tenía la redacción de cartas por parte de los suicidas; dicho de otro modo, cuál era el rol que jugaban estos escritos en diversas circunstancias, y qué significados transmitían a los integrantes de la red social del que se quitaba la vida 6 . Con este propósito, consultamos los textos legados por los suicidas a sus otros significativos ${ }^{7}$.

Durante la elaboración de los sumarios, algunas notas suicidas fueron incorporadas como parte de los expedientes ${ }^{8}$. Otras veces, quedó registro

${ }^{5}$ La categoría marco axiológico fue elaborada a partir de la investigación llevada adelante por el rabino Dr. Fernando Szlajen, quien analizó la reflexión filosófica sobre el suicidio en el pensamiento occidental, y en la filosofía judía, sin reducir el fenómeno a su aspecto psiquiátrico o patológico, y tomó como eje el análisis de la muerte voluntaria como problema ético y existencial (Szlajen, 2012).

${ }^{6}$ Para una síntesis y una reflexión teórico-metodológica de los usos del concepto de "red" en Ciencias Sociales, véase, entre otros: Reguera (2017).

${ }^{7}$ Para una reflexión desde una perspectiva historiográfica sobre las notas y cartas de los suicidas como fuentes históricas, véase entre otros, el reciente trabajo de Mario Fabregat y Daniela Belmar (2020). Los autores recopilaron un conjunto de escritos encontrados en los expedientes judiciales de Chile (entre los años 1880 y 1937). A partir de estos textos elaboraron un análisis crítico de las posibilidades, características y limitaciones a la hora de trabajar estas fuentes históricas. Sobre este tema consultar también Arroyo (2018, 2020a y 2020b).

${ }^{8}$ En este período, el suicidio no era penado por la ley. El Código de la Provincia de Buenos Aires, sancionado en 1877, penaba la instigación o la ayuda al suicidio. En el código nacional, aprobado en 1886, no había ninguna mención sobre el suicidio. Años más tarde, por la ley 4189 del 20 de agosto de 1903, se incluyó en el Código Nacional, de nuevo, la normativa sobre la instigación o ayuda al suicidio. Sobre este tema véase, entre otros: Laplaza (1978); Gardella (1968) y Di Gresia (2014, pp. 455, $457,458-461,794-797,799-803,805-810$ ). Por otra parte, aunque el suicidio no era castigado por la justicia, hasta que no se demostrara que no se trataba de un homicidio, las autoridades judiciales y los agentes de la policía indagaban las causas 
de la existencia de los escritos y alguna información del contenido, pero no fue anexada la documentación original. En ciertas situaciones, el suicida dejó una carta para la policía y el resto de las notas en sobres cerrados, para que fueran remitidas a quienes estaban destinadas; en algunas ocasiones, estos últimos brindaban información sobre el mensaje o la idea general del escrito. Si las cartas eran encontradas en el domicilio del suicida, o entre sus ropas, miembros de la familia o sus amistades solicitaban la entrega de estos textos; tal vez, a modo de guardar el último recuerdo del difunto, o de evitar que el contenido de las notas fuera dado a conocer en los medios gráficos de la época.

En la mayoría de los casos, vale la pena mencionar que los expedientes consultados no contenían escritos o referencias a las notas dejadas por los suicidas. De los 722 sumarios relevados, 180 guardaban cartas en su interior, o alguna referencia acerca de su existencia por parte de los agentes de policía y los que declaraban. Al mismo tiempo, hallamos que la mayoría de los suicidas que dejaron carta fueron hombres (156 casos, 86,67\%). Si bien esto no es sorpresivo, porque la mayoría de los suicidas eran de género masculino, encontramos una leve diferencia si comparamos esta cifra con la proporción de suicidios masculinos dentro de la totalidad de los sumarios analizados $(78,18 \%)$. Como contraparte, mientras que las suicidas representaban el $21,82 \%$ en el total de los casos estudiados, las que dejaban cartas tenían una representación menor en el conjunto (13,33\%, 24 casos).

Debido a que en trabajos previos hemos observado diferencias relacionadas con las representaciones, actitudes y prácticas vinculadas con los actos suicidas de hombres y mujeres, consideramos pertinente indagar si las notas elaboradas por los actores sociales de cada sexo tenían características distintivas, o habían sido elaboradas en circunstancias específicas. Para avanzar en esa dirección (aunque solo sea de manera parcial y limitada) un primer paso fue identificar las principales explicaciones verosímiles de los suicidios. Si bien no conocemos con certeza todos los detalles de la biografía del suicida y los conflictos que lo desesperaban, reconocemos ciertos temas que eran mencionados por testigos, policías y los propios suicidas para dar cuenta de lo sucedido. De este modo, al relevar las distintas explicaciones verosímiles, observamos que

de una muerte violenta. De allí la existencia de expedientes judiciales que contienen la investigación sumaria y las declaraciones en casos de suicidio. 
determinadas situaciones y eventos conflictivos eran mencionados en los sumarios que contenían la mayoría de las cartas, más allá del contenido específico de las mismas. En este sentido, cabe destacar que, en los sumarios referidos a los varones que dejaron previamente algún escrito a sus deudos, las principales variables, causas o motivos registrados, en orden descendente, fueron los siguientes: mal estado de los negocios (12 casos, 7,69\%), pobreza (11 casos, 7,05\%), cansancio / aburrimiento / hastío de la vida (11 casos, 7,05\%), asuntos de reputación (10 casos, 6,41\%), patologías mentales (8 casos, 5,13\%) (Véase la Tabla 5). Asímismo, si analizamos cada una de estas circunstancias / causas / motivos verosímiles, en los casos que figura el "mal estado de los negocios" (26 expedientes) en el 46\% (12 sumarios) encontramos algún escrito legado por el suicida. También destacamos la proporción de notas encontradas en los expedientes que figuran asuntos de reputación (acusaciones, calumnias, sospechas de robo o estafa, vergüenza por no poder pagar las deudas, etc.): de 17 sumarios asociados con estas circunstancias encontramos cartas en 10 (alrededor del 59\%). En el caso de los suicidios de sujetos de sexo femenino que dejaron notas, por otra parte, las explicaciones más frecuentes de los hechos fueron: conflictos con la pareja (4 casos, 16,67\%), cansancio / aburrimiento / hastío de la vida (3 casos, 12,50\%), desengaño amoroso ( 3 casos, $12,50 \%$ ), conflictos familiares ( 2 casos, $8,33 \%$ ) y amores contrariados ( 1 casos, 4,17\%). Así, en los casos analizados, se reiteraban algunas situaciones mencionadas en los expedientes de los suicidas de género masculino (enfermedades mentales y físicas, pobreza, cansancio de la vida), pero, a diferencia de los varones, los actos suicidas de mujeres eran explicados, la mayoría de las veces, a partir del malestar en las relaciones de pareja o de la frustración de sus expectativas amorosas.

Estos últimos son los casos que estudiamos en esta oportunidad, a fin de observar el contenido de los mensajes escritos por las suicidas y su relación con el horizonte femenino de expectativas de la época 9 . Al mismo tiempo, al indagar estos referentes empíricos también prestamos especial atención a dos cuestiones. En primer lugar, los distintos tipos de enunciados

\footnotetext{
${ }^{9}$ Inspirados en el juego de escalas propuesto por los estudios microhistóricos, nos parece relevante una mirada que nos permita conocer las estrategias, las prácticas posibles y las diversas tentativas ensayadas por los actores sociales en diferentes situaciones concretas, y aportamos, de este modo, a la construcción de una mirada dinámica y activa de las acciones de los sujetos, que contemple la comprensión de sus valores y motivaciones. Sobre microhistoria, véase, entre otros: Ginzburg (2004).
} 
transmitidos en las notas (declarativos, expresivos, regulativos agresivos, regulativos oblativos, etc.). Asimismo, indagamos si la suicida se hacía responsable de lo sucedido, 0 , por otra parte, culpaba, directa 0 indirectamente, a otros de sus actos ${ }^{10}$.

\section{Las últimas palabras de las mujeres desgraciadas}

\section{Tuya hasta la tumba...}

Tanto por la extensión de las notas que quedaron preservadas como por la riqueza de su contenido, consideramos oportuno empezar por el caso de Mercedes Anthony (22 años, argentina, soltera). Antes de analizar estos escritos es conveniente presentar la información relacionada con su suicidio. Según los datos del sumario policial, el 6 de enero de 1875 Mercedes se dio un disparo con un arma de fuego en la cabeza. El revólver que usó pertenecía a su pareja, Arturo Massoni (22 años, argentino, empleado provincial, soltero). Arturo y Mercedes vivían en la habitación de una casa de inquilinos.

Como señala Scobie (1977, p.192), la vida del conventillo no dejaba demasiado espacio para la privacidad: "Cada unidad o habitación disponía de alguna intimidad mientras la puerta permaneciera cerrada y una cortina cubriera la única ventana que daba al patio". Los vecinos conocían detalles de la vida diaria y las dificultades de los que habitaban el mismo domicilio. La dueña del inquilinato, la Sra. Juana Balladares, declaró que Massoni presentó a Anthony como su esposa, que vivían en completa armonía y que diariamente volvía a su casa por las noches, salvo por los últimos días. Si bien escuchó el disparo, pensó que venía de la calle, por otro lado, al ser

${ }^{10}$ Sobre este asunto, reflexionamos a partir de las ideas presentadas por Daniela Belmar (2018, p. 95) acerca de las actitudes de los suicidas a la hora de tomar responsabilidad por sus acciones. Belmar, al estudiar los casos de suicidio de Santiago de Chile y San Felipe, entre 1920 y 1940, observó que mientras los varones tendieron a hacerse responsables de su acto suicida y las circunstancias que los motivaron a llevarlo adelante, las mujeres, en cambio, hicieron responsables de sus acciones a otras personas o a factores externos. Como veremos a continuación, al consultar la documentación, si bien podemos observar cierta tendencia de las mujeres a responsabilizar a terceros por sus actos suicidas, también encontramos casos más ambiguos, es decir, suicidas que tomaban responsabilidad en sus cartas, o no se referían al asunto, pero que habían culpado a otros de forma oral, al comunicar sus intenciones suicidas. 
una mujer sola no intentó averiguar qué había sucedido. Al día siguiente, alrededor de las diez de la mañana, Balladares encontró a Mercedes ya sin vida. De acuerdo a las declaraciones de los testigos, y a las cartas adjuntadas en el expediente, hacía varios días que Arturo no volvía al hogar que compartían. Ese mismo día (5-11-1875), fue a declarar a la comisaría su pareja ${ }^{11}$. Según Massoni, había empezado una relación con Mercedes hacía un año y medio, y desde entonces vivían juntos. El tiempo que duró el vínculo habían "vivido siempre en perfecta armonía, salvo alguna vez que por celos han tenido disgustos de poca importancia".

Massoni también declaró que se ausentó por cinco días, pero no detalló las razones de su ausencia, salvo por la noche del 4 de noviembre. Ese día recibió un papel de parte de Mercedes donde le expresaba que sino volvía se quitaría la vida. Como tenía que asistir a una tertulia, mandó decir ("de palabra") a Mercedes que no podía ir. Massoni nunca tomó en serio las intenciones de quitarse la vida de su pareja, pensó que era una especie de llamado de atención, una "farsa". La tertulia a la que asistió Massoni empezó a las 22:30 de la noche y terminó a las 4:30 de la mañana del día siguiente, a esa hora todos se fueron a dormir y también lo hizo Massoni. A las 10 de la mañana, fue avisado del suicidio de Mercedes y decidió buscar a José Rivara, uno de sus amigos y vecino de la casa de inquilinos, para que lo acompañara a corroborar lo sucedido. Según Rivara, Massoni estaba "afligido" por toda la situación y lo que vio al entrar en la habitación debió impresionarlo ya que decidió irse, "disgustado" por la escena. Rivara encontró la carta de Mercedes en su mano izquierda, y, en un primer momento pensó en introducirla en un sobre cerrado y entregarla a Massoni; sin embargo, optó por darle la nota a su amigo directamente. En el relato del sumario no quedó aclarado a qué carta se refería Rivara, y en el expediente fueron adjuntados varios papeles. Es probable que se refiriera al siguiente mensaje:
Querido arturo
Tu me has contesta
do que es inutil que te mande
decir que vengas no se que
motivo tan grande negro
yo te hedado para no in
porta talves mañana cuando
veas mi cadaver no te

${ }^{11}$ AGN, FTC-PE, Legajo A5, Anthony, Mercedes. 
pase

Tuya que va a morir

por ti

Tuya hasta la tumba

Mercedes Anthony

Noviembre 41875 (sic).

De acuerdo con los testigos y la policía, cuando encontraron el cuerpo, Anthony sostenía un papel, en una mano, y, en el pecho, un retrato de Massoni que tenía escrito en el dorso: "Por este muero hoy, 4 de noviembre de 1875 ". Esta foto también fue incluida en el sumario.

Las ausencias de Arturo inquietaban a Mercedes, así lo expresaba en las notas adjuntadas en el expediente:

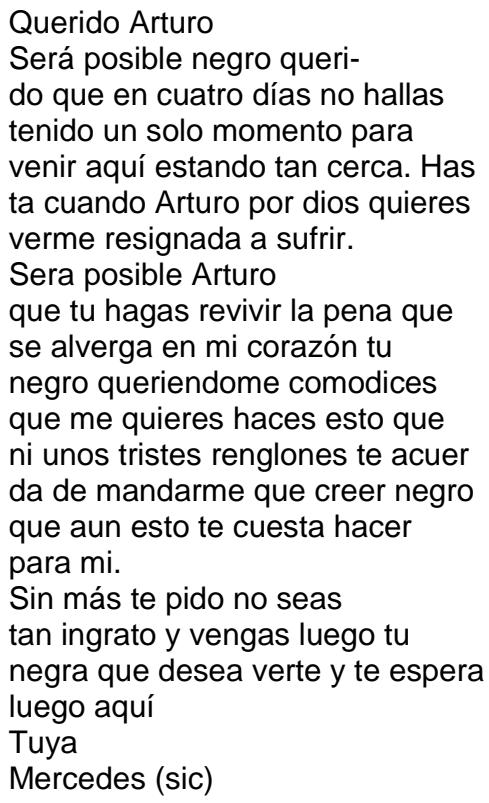

En una segunda carta, Mercedes destacó la ausencia de su pareja (su "querido negro") y manifestó sus sentimientos de inseguridad ("Ya que tu no te dignas venir por que parece que te cuesta o que tu corazón te pida un imposible" -sic-) y le expresó a Arturo que notaba su indiferencia hacia ella, y también que la visitaba "solo por cumplir". Al mismo tiempo, Mercedes le 
informaba que, como él se la pasaba divirtiéndose, no tendría inconveniente en que fuera a pasear con su amiga Petronilla. De todos modos, el mensaje finalizaba marcando que Arturo podía objetar esta salida. En otros papeles encontrados en la habitación, Mercedes manifestaba que no podía "resistir este golpe" (la ausencia de Arturo), y, para no sufrir, expresaba que "más vale morir que vivir desesperada".

En otras cartas adjuntadas al expediente encontramos mensajes de Mercedes hacia Arturo antes de que empezaran los conflictos en la pareja. En uno de los documentos, fechado el 28 de enero de 1875, Mercedes solicitaba a "su negro" que le diera permiso para ir a la casa de alguien llamado Fernando ("si es que tu quieres ire si no no voy" -sic-), y para visitar a unas amigas suyas que vivían en la calle Lima ("con quien pienso ir si es tu gusto el que vaya"). En esta nota Mercedes se despedía con estas palabras: "Tu negra que desea abrasarte y que no hay instante en esta vida que no pienso en ti y te quiere de corazón. Mi querido negro Arturo". En otra de las notas adjuntadas al expediente, Mercedes saludaba a su "idolatrado negro", le deseaba a la madre de Arturo y a este último que pasaran "un día feliz": "no hay dicha más feliz Arturo que estar al lado de lo mas sagrado en la tierra que es la madre que nos da el ser que tenemos" (sic). En la misma carta, Mercedes solicitaba a su pareja que le enviara cuarenta pesos, y le pedía: "Sin más negro adorado espero que no faltes esta noche que tu negra Mercedes te espera. Tuya hasta el postrer momento".

En las notas dejadas por Mercedes Anthony encontramos varias referencias a los principios axiológicos que regulaban las formas de interactuar de la pareja y configuraban el horizonte femenino de expectativas. Desde esta perspectiva, la obediencia era una forma de demostrar afecto por parte de las mujeres hacia los varones, como ha observado María Bjerg (2019) al estudiar los vínculos conyugales de los inmigrantes en las décadas finales del siglo XIX. De acuerdo a lo enunciado por Mercedes en las cartas, los valores asociados con las relaciones de pareja eran muy similares entre extranjeros y nativos. Por un lado, la mujer expresaba ser una pertenencia exclusiva del varón, como una forma de manifestar su cariño incondicional. Al mismo tiempo, proyectaba a su pareja como un proveedor material. Por otra parte, vemos que los celos tenían un papel clave en las interacciones entre Arturo y Mercedes. Las salidas de Arturo a las tertulias y encuentros nocturnos despertaban los celos en Mercedes; ésta, a su vez, buscaba inquietar y poner celoso a su pareja, al destacar que saldría sola también, 
aunque siempre mantenía sus veladas amenazas en el marco de la obediencia al varón.

Otros datos importantes que encontramos al leer este relato son las acciones de los testigos. Rivara, al ver la carta dirigida a Arturo, intentó ponerla en un sobre cerrado. De este modo, podría preservar la intimidad de su amigo y su pareja, como hemos observado en otros sumarios. En estos casos, quedó sentado que el policía entregó la carta a sus destinatarios, y, por esta razón, no figura el documento original ni el contenido de los mismos. Por otra parte, más allá de la exposición de la vida conyugal de Massoni y Mercedes, es probable que Rivara también fuera consciente del impacto que tendrían las cartas en la reputación de su amigo. En este sentido, en las notas legadas por Mercedes, además de expresar la pena y el dolor que sentía por la ausencia de Arturo, la suicida dejó registrada su intención de hacer responsable de su muerte a su pareja, de culparlo por lo sucedido (una acción comunicativa regulativa y agresiva) y exponer su falta en público. Así, si bien el destinatario principal de las acciones comunicativas fue el cónyuge ausente, podemos observar que había una intención de hacer responsable al otro por lo sucedido, es decir, había también una acción comunicativa hacia los otros, un mensaje que la posicionaba como la víctima del abandono y el descuido de su pareja, que la había ignorado y había permanecido ausente por días.

\section{El miedo al desamparo}

Laureana Peralta (argentina, entre 22 y 25 años, viuda) también buscó hacer responsable a un tercero de su acto suicida: Agustín Olivera, su cónyuge. Peralta llevó adelante varios intentos de suicidio. En el primero, el 10 de abril de 1881, Laureana tomó una disolución de fósforos en agua. Arrepentida de beber el veneno, mandó llamar a sus familiares. En el mismo inquilinato vivían Adelina Leiva (prima de Laureana) y los miembros del matrimonio Cairo, Dolores y José. Estos expusieron que, ese día, Laureana fue a entregar una nota a Olivera; al regresar, expresó sus deseos de acostarse y se dirigió a su cuarto. Al ingresar allí, Dolores halló a Laureana tendida en el suelo, largando espuma por la boca; cerca de su cuerpo estaba la taza quebrada con los fósforos diseminados a su alrededor. Según las declaraciones de los testigos, los motivos detrás de este incidente eran los conflictos entre Olivera y Laureana ${ }^{12}$. Peralta dejó tres

${ }^{12}$ AGN, FTC-SE, Legajo P22, Peralta, Laureana, s/suicidio. 
escritos antes de intoxicarse. Uno estaba dirigido a su prima, Adelina. A través de esta carta, le comunicaba sus intenciones de suicidarse "para dejar de sufrir". Al mismo tiempo, le pedía que encontrara a Agustín y le diera en mano una nota dirigida a éste. Laureana también solicitaba a su prima, en nombre de las cenizas de la madre de Adelina, que avisara lo ocurrido a su padre. Por último, le imploraba su perdón y se despedía no sin antes desear felicidad para su prima. La segunda carta era más breve. Estaba destinada a José y Dolores; Laureana explicaba que se quitaba la vida para terminar con su sufrimiento, les pedía que buscaran a Agustín y le informaran lo sucedido. La carta dirigida a Agustín Olivera también fue incluida en el expediente. Por lo que la suicida relató en este escrito, su compañero le lanzaba acusaciones de infidelidad de forma injustificada; por esta razón, estaban separados desde hacía tres meses. Laureana, por su parte, le juraba a Agustín, "por la hostia sagrada", que ella siempre había sido fiel. Al mismo tiempo, pedía disculpas si lo había agraviado, pero no buscaría el perdón por mentiras, chismes e injurias. En esta nota, además de enviar el último adiós, también le solicitaba que la recordara, que guardara sus cabellos en un sobre. Laureana se presentaba como la víctima: la mujer "desgraciada", abandonada por su cónyuge, había sufrido frío y hambre por este motivo; este destino no era justo para ella, que había permanecido siempre al lado de Agustín.

El segundo intento de suicidio llevado adelante por Laureana ocurrió el 18 de marzo de $1882^{13}$. Pese a los celos y los conflictos, el vínculo entre Peralta y Olivera perduró y volvieron a convivir. Pero, de acuerdo con lo que leemos en los documentos, las peleas y los sentimientos posesivos llevaron de nuevo a la separación de la pareja. Al momento de los hechos que narra este expediente, Laureana vivía en otro inquilinato. Para llevar adelante su acto suicida, bebió una disolución de fósforos en kerosén. En esta ocasión, fue encontrada por una amiga, Juana Salvadores. A esta última iba dirigida una de las notas que dejó Laureana. En este escrito le transmitía su decisión: "Me quito la vida por que me encuentro demaciado desesperada y avandonada" (sic). Laureana expresaba su desesperación y no brindaba demasiados detalles ya que Juana estaba al tanto de lo que la afligía ("V. lo save el estado mio cual es Juana" -sic-). Luego de disculparse, "siento mucho de darle un disgusto tan grande", la suicida pedía a su amiga sus últimos favores: en primer lugar, que no diera a conocer a otros lo sucedido y que fuera directo a la imprenta a buscar a Agustín, el sabría qué hacer.

${ }^{13}$ AGN, FTC-SE, Legajo P23, Peralta, Laureana, por tentativa de suicidio. 
Por último, se despedía pidiendo perdón si la había ofendido de alguna manera.

En el expediente, asimismo hallamos un escrito destinado a Agustín Olivera. En dicha nota, una vez más, podemos reconocer la intención de generar culpa y remordimiento en su ex-pareja: "hoy 18 de marzo de 1882 es el último día de mi vida causa tulla y de mi quirido compadre Carranza" (sic). Frente a los chismes y las falsas acusaciones, Laureana respondía:

Agustín yo muero con mi conciencia lipia por que creo de no averte ofendido a vos de ningun modo por que si es respeto a la gran calunia que me ha levantado mi compadre no lo es cierto y lo apruebo con mi vida (sic).

No podemos saber qué tipo de vínculo tenían Laureana y Carranza, pero a éste también lo hacía responsable de su muerte; sin embargo, al mismo tiempo, le otorgaba su perdón. En esta carta, Peralta solicitaba a su expareja una serie de favores. En primer lugar, que no avisara lo ocurrido a sus familiares (eran muy "ingratos" con ella). En segundo término, pedía que llamaran a su madrina, para que se ocupara de sus restos. Asimismo, solicitaba a Olivera que pagara sus deudas ("te pido de favor que le pagues a Juana docientos pesos para que pague su relo[reloj] que lo empeño para darme a mi para que me mudara y también le pagaras a lopes catorce pesos que le pedí emprestado" -sic-). Por último, le pedía que le diera el último adiós el día de su entierro. Al igual que en el primer conflicto, Olivera ponía en duda la fidelidad de su pareja. Nuevos rumores le habían llegado. Una vez más, de acuerdo con la versión de la suicida, estas acusaciones eran falsas; la narración, desde este punto de vista, la posicionaba como la víctima: su honra había sido puesta en cuestión, injustamente, y por este motivo era abandonada por su compañero, que la dejaba desesperada y desamparada, sin poder satisfacer sus necesidades materiales y afrontar sus deudas. Al mismo tiempo, podemos entrever el deseo de generar culpa en Olivera por terminar con la relación y separarse. En este sentido, en la carta también figuraba lo siguiente: "Agustín hasta donde ha llegado tu ingratitu de haber permitido que yo me quite la vida antes de pagarme una triste y micerable pieza sin mas me despido de vos para siempre y te deceo toda la felicidad" (sic). Al parecer, Agustín tal vez se negó a dar socorro a su ex-pareja y no dio relevancia a las amenazas que ésta última le expresó. Como vimos también en el caso de Mercedes, Laureana resaltó en sus notas el rol de proveedor material que debía desempeñar su pareja. 
Cabe destacar que la situación del mercado laboral de las mujeres durante las décadas finales del siglo XIX era muy asimétrica, en comparación a la de los varones. Así, las mujeres, en su mayoría, estuvieron excluidas del mundo laboral masculino, como señala Lobato (2000, p. 470), y muchas siguieron ocupadas como tejedoras, modistas, domésticas, cocineras, planchadoras, lavanderas, costureras y, en algún caso, vendedoras de cigarrillos. Algunas también se dedicaron a ejercer la prostitución. Las que llevaban adelante labores análogas a las de los hombres eran consideradas mano de obra barata, al igual que los niños, y por esta razón cobraban un salario bastante menor que los varones. En este sentido, si bien hubo oportunidades de ascenso social en las décadas finales del siglo XIX, éstas estuvieron reservadas a los varones. Al mismo tiempo, como señala Lobato (2007, p. 78), la cultura dominante estigmatizaba el trabajo femenino. Así, este marco social y cultural contribuía a reforzar la dependencia material de las mujeres hacia los hombres con los que estaban vinculadas. En este sentido, es probable que el miedo al abandono de varias de las suicidas tuviera implícito el temor a las dificultades para la subsistencia que sobrevendrían tras la separación.

Volviendo al escrito legado por Laureana, éste, tal vez, era parte de la venganza final de la suicida: quizás tenía por objetivo producir sufrimiento en la persona que la había abandonado, cuando leyera sus últimas palabras. A diferencia de otros relatos, la nota fue archivada junto con el sumario. Agustín no consideró valioso este documento, tal vez tampoco estimó que su reputación estuviera en juego. En este sentido, la madre de Olivera explicó que las acciones de Laureana parecían responder a la manía suicida, ya que ésta había sido la tercera tentativa de la joven. ¿Qué credibilidad podía tener una alienada?

En suma, Laureana Peralta no tomó responsabilidad por su suicidio. En sus escritos culpaba a su pareja de lo sucedido. Al mismo tiempo, se posicionaba como una mujer fiel, en oposición a las injurias lanzadas a su persona por terceros, que habían puesto en duda su honra y habían motivado las sospechas de su compañero, Agustín, sobre sus sinceros sentimientos. Si bien el otro significativo principal de las cartas fue la pareja, en el segundo intento, Laureana también dejó notas a una de sus amigas, Juana. En esta carta, por un lado, la suicida buscó expresar la desesperación, comunicar las últimas voluntades a una persona de confianza y pedir perdón. Las intenciones y el rol de esta carta fueron similares a las legadas a su prima, Adelina, y a los vecinos de la casa de 
inquilinos, José y Dolores, en su primer intento de suicidio. En este sentido, podemos observar el rol de las amigas en la vida de Laureana, eran las confidentes de su situación sentimental, personas a las que podía recurrir para depositar sus últimas voluntades. Al mismo tiempo, expresaba su afecto, les deseaba felicidad y les pedía perdón. A diferencia de Mercedes Anthony, Laureana tenía más presente el recuerdo que legaría a los que la conocieron. Si bien no dejó de hacer responsable a Olivera por su acto suicida, y buscó culparlo por haberla abandonado, también expresó, de forma explícita, que había sido una mujer fiel y su deseo de ser perdonada por el malestar que generaría entre sus vínculos.

Por otra parte, a veces, detrás de palabras que podían parecer más amables o neutras había historias en las que la suicida buscaba condicionar a su entorno. Por ejemplo, cuando Matilde González (modista, española, año y medio de residencia, 33 años) intentó quitarse la vida (al tomar una disolución de fósforos) y dejó una carta con el siguiente mensaje:
A la justicia nada
Tienen que justificar
a nadie Quiero mori
y Tomo Estas medi
das de en benenar
me yo
Matilde Gonzalez (sic)

Este episodio tuvo lugar el 31 de octubre de $1886^{14}$. Ese día, la pareja de Matilde, Pablo Rauch, la encontró padeciendo vómitos y dolores en el vientre. Momentos más tarde confesó que había tomado fósforos diluidos en ginebra ${ }^{15}$. La motivación de su autoagresión: Rauch se iba a la campaña, al día siguiente, por dos meses. Matilde había dejado la casa de su familia para irse con su amado, en contra de la voluntad de sus padres, que desaprobaban la relación que tenía con su pareja. La suicida declaró al policía que prefería morir a permanecer dos meses sola, mientras su compañero salía a la campaña. Esta situación era inaceptable para Matilde;

\footnotetext{
${ }^{14}$ AGN, FTC-SE, Legajo G37, González, Matilde, s/tentativa de suicidio.

${ }^{15}$ En el conjunto de los 724 casos estudiados, el medio más utilizado para quitarse la vida fue el arma de fuego $(352,48,62 \%)$ y, en segundo lugar, el envenenamiento (154, $21,27 \%$ ). Los venenos eran utilizados de forma más habitual por individuos del género femenino, los hombres, por su parte, recurrían, con más frecuencia, al revólver u otro tipo de arma de fuego, y, en segundo lugar, a los objetos cortantes.
} 
sin embargo, no optó por dejar una nota para su pareja. Sólo consideró relevante o conveniente escribir una carta para no comprometer a terceros con su muerte. En este escrito, dirigido al comisario, Matilde tomaba responsabilidad de lo sucedido. El mensaje para Rauch, por otro lado, estaba incluido en el acto suicida que su cónyuge llevó delante de él. Cabe mencionar que el médico que atendió a la suicida dio a entender en su informe que no encontró signos de envenenamiento, a excepción de los vómitos. Al mismo tiempo, informaba que la mujer estaba un poco exaltada debido a las bebidas alcohólicas que había consumido. Es decir, el profesional de la salud exponía indicios de que Matilde no trataba de suicidarse sino de llamar la atención de su compañero. Es posible que intentara disuadir a su pareja para que no se fuera de la ciudad. Quizás temía ser abandonada, y no contar con los recursos para subsistir, o que cabía la posibilidad de que Rauch no le enviara dinero en esos dos meses. También es probable que temiera sentirse sola, no hacía mucho que vivía en una tierra nueva, no sabemos cómo era su red vincular, si había logrado integrarse de alguna forma, o si el único vínculo relevante era su pareja. A diferencia de otros casos donde aparecieron cartas o referencias a amigas o familiares de sexo femenino, no encontramos este tipo de relaciones en el relato de este acto suicida.

En el caso de Eleonora Florents, aparecen este tipo de escritos, pero muchas de las cartas que dejó, antes de quitarse la vida, estaban dirigidas a la red de vínculos que había quedado del otro lado del Atlántico. Eleonora (25 años, prostituta retirada, francesa) venía de Lyon y en un prostíbulo de esta ciudad había conocido a su pareja, G Benoit Mayer. En febrero de 1886, aquel estuvo de nuevo en Francia, y Eleonora le insistió para venirse con él a Buenos Aires. Al tiempo, le escribió pidiendo dinero para cruzar el océano. Eleonora llegó a la capital del estado argentino en agosto de 1886. Vivían en la "mejor armonía" hasta que tuvieron un disgusto (que no se menciona en el sumario) y Mayer le propuso que volviera a Lyon, él le daría el dinero para que se fuera de vuelta a Europa. Eleonora no le contestó, pero a partir de entonces empezaron a ocupar habitaciones separadas, sin que su concubina demostrara tristeza. La noche anterior, Eleonora se puso a escribir, mientras cantaba de a ratos. El 2 de mayo de 1887, en la casa donde convivían, la suicida se disparó en el corazón con un revólver. La carta que dejó a Mayer no figura en el expediente. En ella, según el policía, Florents le pedía que enviara sus bienes a Francia para pagar una deuda que tenía con la dueña del prostíbulo donde había trabajado, y que cuidara a un loro y un gatito que tenían en la casa. Eleonora también dejó otras 
cuatro cartas dirigidas a personas de la ciudad de Lyon, un par eran para dos mujeres (una de ellas tenía el mismo domicilio que el prostíbulo donde había trabajado la suicida), las restantes eran para dos individuos de género masculino. Estas notas no fueron adjuntadas al expediente y nada se dice sobre su contenido.

Es probable que frente al abandono, y al horizonte de volver al mundo de la prostitución, Eleonora sintiera una profunda desilusión. Como mencionamos antes, muchas mujeres no contaban con otras alternativas frente al desempleo y la falta de oportunidades laborales. En este sentido, Donna Guy (1994, p. 85) señala que, en general, las prostitutas de origen extranjero habían quedado por fuera de los trabajos capitalistas en las fábricas, del otro lado del Atlántico. Al mismo tiempo, podemos destacar también, de acuerdo con lo expuesto por Guy (2014, pp. 121-122) en un trabajo más reciente, que la prostitución no era la principal actividad de las mujeres suicidas, aunque compartían con el resto de los suicidas de sexo femenino similares condiciones habitacionales (vivían en piezas alquiladas), padecían de enfermedades físicas y/o mentales, y sufrían la ausencia de redes de contención suficientes. Como señala la autora, podría aventurarse que las que trabajaban en burdeles tenían mayores vínculos a los que recurrir para afrontar las dificultades que las mujeres que ejercían la actividad solas y en la clandestinidad. En el caso de Eleonora, el tiempo que estuvo en Buenos Aires no había sido suficiente para generar nuevos lazos que sirvieran de marco de contención frente al abandono de su pareja. Al leer lo relatado en el expediente, podemos observar que su red de contención estaba muy lejos de Buenos Aires. Un signo de esto último es que las cartas que dejó eran para su red de vínculos en Francia. A esos otros significativos fueron dedicadas sus últimas palabras.

\section{Deshonradas y abandonadas}

En el caso de Delfina Campaloneri (19 años, italiana), la suicida apuntó como responsable de su desgraciada y extrema resolución a la persona que le generó un desengaño amoroso ${ }^{16}$. El 4 de febrero de 1888 intentó quitarse la vida al ingerir una disolución de fósforos en agua, luego de enterarse que el joven con el que mantenía un vínculo romántico le había sido infiel y estaba en una relación con otra persona. En la carta que dejó, Delfina manifestaba que se sentía deshonrada, pedía perdón a Dios y a su familia.

${ }^{16}$ AGN, FTC-SE, Legajo C46, Campaloneri, Delfina, s/tentativa de suicidio. 
Al mismo tiempo, les manifestaba que lamentaba morir, dejaba este mundo por el joven que la había engañado, moría por él, aunque ella lo perdonaba "de todo corazón" por todo lo que le había hecho. Así, con este último epitafio, Delfina descargaba la responsabilidad de su suicidio en aquel seductor que la había deshonrado. Al mismo tiempo, buscaba el perdón y la compasión de sus afectos, de su familia y amigos ${ }^{17}$.

Melania Reymond de Gondran, en cambio, expresó que había perdido su honra, y asumía la responsabilidad por ello, sin dar a conocer los hechos y los detalles de sus desgracias. Estos penosos eventos de su biografía ya eran conocidos por su red de vínculos. Por esta razón, estaba convencida de que su compañero, Musiliar Lanci, la abandonaría ${ }^{18}$. Melania había estado casada con un hombre de apellido Gondran, hasta que conoció a Lanci. En ese momento, dejó a su esposo, en Francia, y decidió irse con su amado. Lanci trabajaba como músico y convivía con Melania y el hijo de aquella y su ex marido, que tenía 6 años de edad. Cuando declaró, la madre de Melania explicó que los familiares no avalaban los "amores ilícitos" que tenía su hija con Lanci. Por otro lado, remarcó que Melania se había separado de su ex-esposo con autorización de las autoridades eclesiásticas. Reymond se quitó la vida el 22 de febrero de 1882. Ese día, dejó encendido el brasero de la habitación en la que vivía con su familia, cerró la entrada a la pieza y murió por asfixia. Cuando Lanci fue interrogado, explicó, entre sollozos y un dolor manifiesto, que había pedido a Melania que le confesara aspectos íntimos de su vida. Melania accedió y le dio a conocer esta información. Tal vez, la manera en que reaccionó su pareja la alteró: Lanci pensaba que Reymond se había suicidado por miedo a ser abandonada. ¿Cuáles eran los secretos de Melania? ¿Por qué creía que su cónyuge la dejaría librada a su suerte? ¿Había sido infiel? Por lo que figura en el sumario, el músico estaba arrepentido de sus acciones y expresó una profunda tristeza por el desgraciado final de su relación.

Las dos notas que escribió Melania, detrás de las partituras de su compañero, tampoco nos dan muchos datos; éstas fueron presentadas por el diario La Nación ${ }^{19}$, días después de su muerte. Uno de los escritos contenía un mensaje dirigido a su pareja y a todos los que tuvieran conocimiento de su acto suicida. En los enunciados, Melania enfatizaba que

\footnotetext{
${ }^{17}$ Agradezco a Claudia Debernardi por realizar la traducción de este documento.

${ }^{18}$ AGN, FTC-SE, Legajo R21, Reymond de Gondran, Melania, por suicidio.

${ }^{19}$ La Nación, Buenos Aires, 24-02-1882.
} 
su cónyuge no tenía "culpa alguna" de su suicidio y que siempre había sido para ella "un hombre bueno y honrado". También suplicaba el perdón de Lanci por el sufrimiento que le iba a generar con su muerte. Por último, se despedía: "Perdon una y mil veces y si me has amado conservaras un piadoso recuerdo para esta Melania que te ha querido" (sic) ${ }^{20}$. La segunda, dirigida a la madre de la suicida, daba alguna otra información sobre lo sucedido. En esta nota, Melania le encomendaba a su hijo, ya que no estaría para cumplir su rol: "protegerlo y formarlo un hombre", como haría una "buena madre". Al mismo tiempo, le expresaba a su progenitora la culpa que sentía por su deshonra, este sentimiento la vencía. No hay más detalles sobre las causas que generaron este remordimiento, pero es muy probable que la madre de Melania conociera los hechos a los que se refería su hija de forma indirecta:

Sabes que voy por el camino de la desgracia; hoy, vencida por los remordimientos, con la deshonra en perspectiva, que es mas grande que todo, pues que el que se llama mi esposo va a abandonarme y no veo para mi mas camino que la muerte (sic).

En cierta medida, Melania se hacía responsable de su acto suicida, pero, al mismo tiempo, pedía que su madre perdonara a su esposo: "Tu me perdonaras y a el tambien porque yo sola soy la unica culpable - solamente yo" (sic). Por último, en este mensaje de despedida, Melania solicitaba el perdón a su madre: "Adiós, mi querida madre; perdona a esta hija que te ha dado no solo todos los disgustos, sino también toda la deshonra". Melania no explicó qué clase de acciones la habían llevado a comprometer su honor, el de su pareja y el de su familia. En las páginas de La Prensa y La Nación, los cronistas también mantuvieron la discreción: "Las causas del suicidio son de carácter tan intimo que no ha creído conveniente la familia autorizar su publicidad"21. En la noticia del diario La Nación ${ }^{22}$ se mencionaba que: "Hay en las causas que han motivado este suicidio hechos de importancia y de verdadero interés, que omitimos por pertenecer a la vida íntima de aquella desgraciada". Tal vez, Melania confió a su pareja algún episodio de infidelidad que afectaba el honor de éste y, por ese motivo, quizás, Lanci mostró intenciones de terminar el vínculo entre los dos.

\footnotetext{
${ }^{20}$ La traducción de las cartas publicadas en el diario La Nación es fiel al contenido de las notas adjuntadas en el expediente que contiene el sumario. Quiero agradecer a la Traductora Pública Natalia D'Aquino por hacer la traducción de estos documentos.

${ }^{21}$ La Prensa, Buenos Aires, 23-02-1882

${ }^{22}$ La Nación, Buenos Aires, 23-02-1882
} 
En este caso, la suicida tomó responsabilidad por lo sucedido, no sin dejar entrever que llevaba su acto motivada por el abandono de su compañero (pedía a su madre que lo perdonara a él también), aunque se hacía responsable de todo lo sucedido. Sin embargo, la intención principal del último mensaje de Melania fue la búsqueda del perdón, una acción comunicativa regulativa oblativa. Melania sabía que había perdido su honra, aunque no sabemos el motivo, entendía que había comprometido la reputación familiar. Al mismo tiempo, era consciente de que su acto suicida la exponía como una madre irresponsable, que abandonaba su rol en la crianza de su hijo. Frente a estas violaciones del horizonte femenino de expectativas, el mensaje final de Melania era un pedido de redención para ella y para su cónyuge, y dejaba encargada de cumplir sus últimas voluntades a su madre. En este caso, las últimas palabras fueron un modo de resarcirse por quebrantar los ideales y valores del marco axiológico que compartía con su red social. En este sentido, la acción comunicativa persiguió como objetivo salvar la memoria de la suicida entre sus vínculos. Por otro lado, como mencionamos antes, al pedir perdón para su esposo, de algún modo le adjudicó parte de la responsabilidad por lo sucedido, y, en cierta medida, también era consciente del sufrimiento que le generaría a su pareja. Es decir, podemos interpretar que, de forma implícita, había un intento de agresión por debajo de su pedido de perdón, un mensaje que además dejaba expuesto el abandono por parte de Lanci.

A diferencia de Matilde González, Melania Reymond de Gondrán apeló a dos de sus otros significativos, su pareja y su madre, en las cartas que legó. Vemos que esta última desempeñaba el papel de confidente; tenía conocimiento de las acciones pasadas que comprometían la honra de su hija y la de su grupo familiar. Melania sabía que podía encomendarle el cuidado de su hijo. En cierto modo, cumplía un rol similar al de la amiga y la prima de Laureana Peralta. María Madero (23 años, argentina, soltera) también pensó en escribir a sus amigas, antes de intentar quitarse la vida ${ }^{23}$. Además de una carta dirigida al comisario (en la que pedía que no se ocupara en averiguar detalles de lo ocurrido, y, al mismo tiempo, que hiciera todo lo posible por ella) dejó dos notas inconclusas para dos de sus amigas, según consta en el sumario (aunque estas no fueron adjuntadas al expediente). El policía aclaraba que en ellas no se mencionaban las causas del intento de suicidio. El 21 de octubre de 1887, María tomó fósforos diluidos en kerosén. Fue encontrada por el inquilino de la casa que la tenía

${ }^{23}$ AGN, FTC-SE, Legajo M39, Madero, María, s/suicidio. 
como huésped, Simón Becerra, que fue a buscar auxilio. Los doctores de la zona le dieron un vomitivo para que la suicida expulsara lo ingerido. Luego, María fue interrogada por la policía y los médicos pero se negó a decir palabra. No sabemos la relación entre María y Becerra. Éste último explicó a las autoridades que la joven había descubierto que tenía un embarazo de cuatro meses. Al mismo tiempo, el día anterior le habían informado que Juan Coronel (ex sargento de policía y actual ordenanza del banco de la provincia), el hombre con el que estaba comprometida, había contraído matrimonio con otra mujer. En el expediente figura un breve mensaje de Coronel a María; en esta nota le pedía que lo esperara, que el pasaría por su casa "undia destos" (sic). Ya en el Hospital San Roque, María fue interrogada de nuevo por el policía. Allí, explicó que al "verse embarasada y burlada por Coronel" (sic) había atentado contra sí misma tomando la dosis de kerosén y fósforos. El médico que revisó a María, horas más tarde, sospechaba que se trataba más de una simulación de envenenamiento que una tentativa de suicidio, ya que la suicida no tenía los síntomas de la intoxicación. Al volver a los escritos que legó María, podemos entrever que pensó en escribir a sus amigas y, por algún motivo, desistió; así, dejó inconclusos esos últimos mensajes para ellas. Por otra parte, vemos que estuvieron presentes en ese momento de intensa desesperación. Quizás se sentía avergonzada por toda la situación, por la deshonra y por haber sido engañada por Coronel. María no quería declarar, las circunstancias y la insistencia de sus interrogadores la llevaron a revelar aquello que ocultaba.

Así, las cuestiones relacionadas con la honra estaban de fondo en la vida y la biografía de hombres y mujeres. Estas últimas no estaban exentas del peligro de verse deshonradas y sus consecuencias. Por siglos, el cristianismo instituyó un código moral tendiente a regular la sexualidad de los fieles, varones y mujeres. En el caso de las personas de sexo femenino, las pautas eran la virginidad y la fidelidad. La reputación de la mujer también podía ser puesta en duda si los otros observaban un comportamiento poco habitual (salir sola o presentarse en espacios públicos). Al mismo tiempo, como señala Gayol (2000, pp. 188-201), si bien la sexualidad de las mujeres afectaba su propia honra, deshonraba también al esposo, al padre y a los hermanos con su accionar. En este sentido, la joven que había quedado embarazada antes del matrimonio era víctima de un estigma social en la época, ya que su situación afectaba también la reputación de su núcleo familiar. Según Fermín Rodríguez, médico que estudió los suicidios en los últimos años del siglo XIX, 
El abandono por parte del hombre, la represión, a veces sangrienta, de parte de su familia, la miseria y la vergüenza, llevando en brazos al hijo, frecuentemente odiado desde los primeros síntomas del embarazo, amasan esa pasta de la que abandonará, en algunos casos, la existencia, para escapar a las penalidades físicas y morales de una maternidad intolerable, si no se libra ella por el aborto criminal o el infanticidio, cuya idea es insinuada por alguna compañera práctica en esos achaques de las consecuencias del amor clandestino, si acaso no lo es por las narraciones de los diarios, tan pródigos en lecciones de inmoralidad (Rodríguez, 1904, p. 14).

El honor femenino, si bien en un lugar más secundario que el masculino, también era considerado a la hora de pensar las causas y la legitimidad de los suicidios. En este sentido, el autor también se preguntaba si, frente a un caso de incesto, la mujer deshonrada estaba en su derecho de quitarse la vida. Así, el honor de hombres y mujeres daba sentido a algunos de los casos de suicidio que estaban por fuera de las patologías mentales o de las enfermedades morales.

Serafina Iglesias (16 años, española, soltera) temía que su relación tuviera un desenlace similar al de María Madero24. Había venido desde la casa de sus padres en La Coruña, España, a vivir con su tía, Victoriana García, en un inquilinato de Buenos Aires. Estaba en una relación amorosa con un joven llamado Manuel E. Cont. Tanto Victoriana como Cont declararon que Serafina salía con este último hacía seis meses y que nunca tuvieron disgusto alguno. Algunas veces, Serafina le dijo que le habían llegado rumores de que nunca se casaría con ella porque tenía otro compromiso. La joven le manifestó en esas ocasiones que si lo anterior era verdad, "no les habia de dar trabajo pues no pensaba vivir mucho" (sic). Según Cont no se imaginó que llegaría al extremo de quitarse la vida; éste, tal vez, se sentía culpable por no haber reconocido la amenaza en ese momento, o no tomarla en serio. No sabemos si las acusaciones de infidelidad que pesaban sobre el muchacho eran reales o sólo se trataba de comentarios maliciosos que alimentaban las fantasías más tristes y dolorosas en la mente de Serafina, estas hacían crecer sus celos y la incertidumbre sobre sus anhelos y deseos: contraer matrimonio y formar una familia. Estos pensamientos, quizás, habían consumido a la joven.

${ }^{24}$ AGN, FTC-SE, Legajo I2, Iglesias, Serafina, s/su suicidio. 
Lo cierto es que Serafina llevó adelante lo que había comunicado a su pareja. El 13 de junio de 1882 se levantó a las siete de la mañana. Consultó a su tía y a los vecinos si las boticas estaban abiertas en ese momento; uno de los inquilinos, Justo González le respondió que sí. Luego de tomar un café con Victoriana, Serafina escribió una carta. Pidió a su tía dinero para poder hacer el envío a través del correo. Victoriana se lo dio pensando que era para escribir a su familia, del otro lado del Atlántico. No sabía que Serafina lo usaría para comprar una sustancia tóxica conocida como "sal de limón" (ácido oxálico), utilizada para sacar manchas de la ropa. Al volver, la joven encontró a su tía barriendo y se ofreció a hacerlo en su lugar. En ese momento, quedó acompañada por una niña, hija pequeña de Victoriana, que presenció cómo Serafina introducía una sustancia extraña, que tenía en un sobre de papel, en un vaso con agua y bebía su contenido. Al poco rato, pasó por la cocina, en donde estaba una vecina, María Pose, y se dirigió al fondo de la casa para luego retornar a su cuarto. Como Pose la vio pálida y empapada en sudor, fue a ver a Serafina a su habitación. Allí, la encontró sentada en una silla junto a la cama, con la cabeza recostada sobre esta. Al preguntarle que le pasaba, le confesó: "estoy envenenada". Pose salió a buscar un médico, pero cuando este llegó encontró a la suicida sin vida. En la carta que dejó a su tía, Serafina le manifestaba lo siguiente:

Querida Victoriana esta es la primera y sera la ultima pues no pudiendo dar fe ni me de V. porque el cariño me lo impide lo ago des ta ma nera y a demas porque con este papel no conprome to ana dies lo que le pido es que le mande a decir a mi irmana lo que pasa Victoriana lo poco que es para $\mathrm{V}$. no tengo plata pero tampoco la debo; pidan para mi cajón y que me lleven en ese carro de pobre que por pobre no le costará nada; adios para siempre señora ruega a Dios por el alma de esta desgraciada suicidada

Serafina Iglesias (sic)

Tal vez, Serafina esperaba ser rescatada a tiempo, y la ayuda llegó demasiado tarde; quizás buscaba generar alguna reacción en Cont, para que abandonara a su otra candidata y se quedara a su lado. Por otro lado, posiblemente se sentía deshonrada, engañada y avergonzada como otras mujeres que se quitaron la vida. Lo que podemos entrever es que si bien hubo una carta dirigida a su tía, el acto suicida en sí tenía un mensaje para Cont, uno que había sido transmitido de forma oral a éste días antes. Serafina no expuso en público los hechos que la hacían desgraciada en su nota, pero generó las acciones para que su pareja supiera el significado de su suicidio. 


\section{Una buena y fiel compañera}

Como vimos en otros casos, las mujeres que dejaron sus cartas, más allá de dar o no explicaciones sobre las motivaciones de su acto suicida, aprovechaban para transmitir una última despedida. Con sus palabras finales, algunas resaltaban también las cualidades positivas que coincidían con el horizonte femenino de expectativas de la época. Así lo hizo Gregoria López (20 años, argentina) ${ }^{25}$. Gregoria vivía con su esposo, Narciso Pérez. Éste señaló que tenía una buena relación con su mujer: "Vivían tranquilos y jamás cuestión alguna turbó la paz que reinaba en ese hogar modesto", según registró la policía. Por otra parte, Doña Rosa Relli, explicó que Gregoria, el día antes de su acto suicida, le había manifestado que hacía tres años que estaba cansada de vivir y que deseaba morir. El 12 de marzo de 1886, Gregoria falleció tras ingerir ácido oxálico, en la habitación del conventillo donde residía con su marido. Ese día, a las 11 de la mañana, Don Ignacio Manuel, dueño de la casa, vio a Gregoria acostada en su lecho, vomitando. Al comprender lo que sucedía, Manuel salió deprisa a buscar un antídoto, pero, cuando regresó, Gregoria ya estaba sin vida. Su esposo, Narciso, no estaba en ese momento, había salido a su trabajo. También vivía en el mismo inquilinato la madre de Gregoria, Doña Juana López. Juana declaró que la carta encontrada cerca del cuerpo de su hija era la que esta última había escrito el día anterior, por la mañana. En ese entonces, Gregoria le había explicado a su madre que estaba redactando un mensaje para su padre, que vivía en San Nicolás de los Arroyos. Sin embargo, la nota que Gregoria dejó estaba dirigida a su esposo, Narciso. Entre otras cosas, con sus últimas palabras, le expresaba la preocupación por el sufrimiento que iba a generar en su familia. Al mismo tiempo, le comunicaba que su cabeza no estaba bien. Gregoria se despedía de todos sus vínculos, pero no mencionaba los motivos de su suicidio, aunque destacaba que no habían sido "amores". No sabemos si había un conflicto conyugal de fondo, pero Gregoria dejaba en claro que no se trataba del estereotipado suicidio por "amores contrariados", y que no había una conducta deshonrosa detrás de lo sucedido: ella había sido para su esposo una buena y fiel compañera. La preocupación central fue remarcar que ella había sido una mujer que cumplió con su rol de acuerdo al marco axiológico, había sido una leal y virtuosa esposa. Por último, Gregoria encomendaba a Narciso el cuidado de su hijo.

${ }^{25}$ AGN, FTC-SE, Legajo L22, López, Gregoria, su suicidio. 
En el ejemplo anterior, observamos la presencia de discursos vinculados con el horizonte de expectativas femenino de la época. Como explica Mirta Lobato (2007, pp.13, 63, 78, 105 y 315), este estaba asociado con el cuidado del hogar y los hijos, de suma importancia para la generación de los nuevos ciudadanos de la nación. Según el marco axiológico vigente, la misión principal de las mujeres era transformar el hogar en un espacio de abrigo y contención, un refugio que promoviera la felicidad en los integrantes del núcleo familiar. Así, se configuraba la imagen ideal de la madre de familia: señora del hogar, ama de casa, dedicada a su labor maternal, y a asegurar la tranquilidad y la armonía de la casa, mientras que los hombres se recuperaban para volver a la actividad en el espacio público. De acuerdo a esta visión idealizada, la mujer brindaba consuelo, ánimo y protección, al mismo tiempo, era fuente de belleza y vitalidad para su entorno (Lobato, 2007, p. 63). La contracara de esta imagen era la prostituta, la "mujer pública" que había perdido su honor. Así, como mencionamos antes, el comportamiento sexual determinaba la reputación de las hijas, madres y esposas. Por otra parte, la sexualidad de las mujeres también afectaba el honor de los varones con los que estaba vinculada. El esposo, el padre y los hermanos debían ejercer un control sobre ellas y prevenir hechos inmorales y conductas desviadas que pusieran en peligro la honra de la familia (Gayol, 2000, pp. 188-201).

Como hemos observado en las notas que dejaron muchas suicidas, encontramos referencias a estos principios del marco axiológico. Si bien nuestras fuentes nos plantean límites a la hora de adentrarnos en el complejo mundo interno (las emociones y sentimientos) de las mujeres que se quitaron la vida, sí podemos entrever, al menos de forma parcial, indicios de los valores que estaban implícitos en el lenguaje y los enunciados de sus palabras finales. En algunas notas, observamos el interés por manifestar que se había sido una buena mujer, una compañera fiel y obediente. En otros escritos, las mujeres expresaban el dolor que generaba la pérdida del honor o la puesta en duda de su reputación. Al mismo tiempo, en otros casos, podemos ver las palabras de frustración y resentimiento de las que se sentían traicionadas 0 abandonadas por sus parejas ${ }^{26}$. Estas mujeres

\footnotetext{
${ }^{26}$ Para un análisis de los conflictos conyugales de la población inmigrante que arribó al Río de la Plata, en las décadas finales del siglo XIX, puede mencionarse, entre otros, el trabajo de María Bjerg (2019); Sobre la cultura afectiva de las clases trabajadoras, durante este período, véase también: Lobato (2011). Para una historia social de las
} 
veían derrumbarse el anhelo de conformar y/o consolidar ese refugio, ese núcleo familiar en el que podrían desempeñarse como las guardianas de la tranquilidad y la armonía.

\section{Consideraciones finales}

En el presente trabajo analizamos algunas de las notas legadas por las mujeres que se quitaron la vida entre 1859 y 1888, a partir de los casos preservados en los sumarios judiciales del fondo "Tribunal Criminal" de la ciudad de Buenos Aires. Mientras que los escritos de los varones, en su mayoría, aparecieron en relatos de actos suicidas explicados a partir de asuntos de reputación, mal estado de sus emprendimientos comerciales o inversiones, en cambio, las cartas dejadas por mujeres suicidas fueron menos frecuentes que las masculinas y aparecieron, sobre todo, en los expedientes relacionados con peleas con sus cónyuges, desengaños amorosos o amores contrariados.

Varios de estos escritos estaban dirigidos a las parejas de las suicidas. El tono y el contenido de estos mensajes era variado así como las intenciones de sus autoras. Mientras que en algunos culpaban abiertamente a sus compañeros o pretendientes de ser los causantes de sus muertes, en otros casos, las intenciones de hacer responsables a terceros de sus desgracias aparecían de forma más ambigua. Así, en ciertos episodios, la carta en sí no mencionaba el mensaje que la suicida había transmitido de forma oral a sus parejas o a los miembros de su red social. En este sentido, las acciones regulativas agresivas (los mensajes con intención de generar remordimiento en los otros significativos) no siempre aparecían de forma explícita en las notas, estas podían ser llevadas adelante en las interacciones personales con sus vínculos.

También cabe destacar que la expresión de ciertos sentimientos no siempre estaba presente en las notas: algunas suicidas transmitían su frustración y su enojo de forma directa, otras, en cambio, omitían manifestar estas emociones en sus últimas palabras, se limitaban a comunicar que se quitaban la vida, a expresar su pesar, resaltar ciertas cualidades personales positivas de su biografía o a comunicar las últimas voluntades, a modo de testamento. En buena medida, las características del mensaje final

temáticas relacionadas con la vida de las mujeres y las relaciones entre los sexos, durante este período, en Argentina, véase también: Barrancos (2000; 2012), Pita (2009). 
dependían del sujeto a quien se dirigían las suicidas. Dada la situación de conflicto con las parejas en estas narraciones, no es sorpresivo que los descargos y los intentos de sembrar remordimiento estuvieran dirigidos hacia estos. Pero también aparecían combinados con algunas de las otras acciones comunicativas expresivas o regulativas oblativas, orientadas a condicionar el recuerdo y la imagen que construirían los otros significativos. Al mismo tiempo, en las notas que legaron las suicidas vemos cómo representaban a sus compañeros y el vínculo que construían con ellos. Demostrar la obediencia era una forma de expresar afecto. Al mismo tiempo, manifestar la exclusividad de su cariño hacia el hombre que amaban, al dueño de sus corazones, también formaba parte de las demostraciones que daban sustento a las relaciones entre los cónyuges. Si bien, en varios casos, los varones eran acusados de ser los causantes de sus desgracias, con casi igual frecuencia eran representados como sus proveedores materiales. Si ellas cumplían con su rol como mujeres fieles, honradas y obedientes, el varón debía atender sus necesidades y brindarles el dinero para ello.

Por otra parte, cabe señalar que, además de los cónyuges o novios, varias suicidas dejaron notas a otros individuos de género femenino. Así, encontramos por un lado familiares, madres, hermanas, primas, que fueron interpeladas a través de las últimas palabras de las suicidas, en general, como depositarias de sus últimas voluntades y de sus pedidos de perdón, sobre todo, por el dolor que generarían con sus actos. Del mismo modo, otros personajes que ocupaban un papel clave y un rol similar eran las amigas. A ellas también iban dirigidos los encargos y las despedidas de las mujeres que se quitaban la vida.

\section{Bibliografía}

Arroyo, J. (2018), Los significados de la desesperación. Las representaciones del suicidio en Buenos Aires (1868-1903). Tesis de doctorado inédita. Facultad de Humanidades y Ciencias de la Educación, Universidad Nacional de La Plata, La Plata, Argentina.

Arroyo, J. (2020a). "Adiós querida mía, adiós tesoro": Las acciones comunicativas de los suicidas apasionados en Buenos Aires durante el último tercio del siglo XIX. Trabajos y Comunicaciones, (52), 1-17. 
Arroyo, J. (2020b). El significado de las últimas palabras: las notas suicidas como acciones comunicativas. Buenos Aires, 1859-1888. Nuevo Mundo Mundos Nuevos. https://doi.org/10.4000/nuevomundo.82661

Barrancos, D. (2000). La vida cotidiana. En M. Lobato (Dir.). Nueva Historia Argentina (Tomo V) (pp. 553-601). Sudamericana.

Barrancos, D. (2012). Mujeres entre la casa y la plaza. Sudamericana.

Belmar, D. (2018). A nadie se culpe de mi muerte: suicidios entre 1920-1940, Santiago y San Felipe. Ediciones Universidad Alberto Hurtado.

Bjerg, M.(2019). Lazos rotos: la inmigración, el matrimonio y las emociones en la Argentina entre los siglos XIX y XX. Universidad Nacional de Quilmes.

Di Gresia, L. (2014). Instituciones, prácticas y culturas judiciales. Una historia de la Justicia de Paz en la Provincia de Buenos Aires. El Juzgado de Paz de Tres Arroyos (1865-1935). Tesis de Doctorado. Facultad de Humanidades y Ciencias de la Educación, Universidad Nacional de La Plata, La Plata, Argentina.

Durkheim, E. (2004). El suicidio. Estudio de sociología. Editorial Losada [1ํㅡ ed. 1897].

Fabregat M. y Belmar D. (2020). Más allá de la muerte. Recopilación de cartas y notas suicidas (Chile, 1870-1937). Prohistoria Ediciones.

Fitzpatrick, S.(2011). Looking Beyond the Qualitative and Quantitative Divide: Narrative, Ethics and Representation in Suicidology. Suicidology Online, (2), 29-37. https://www.suicidology-online.com/pdf/SOL-2011-2-29-37.pdf

Gardella, L. (1968). Suicidio. Enciclopedia Jurídica Omeba (Tomo XXV). Bibliográfica Omeba.

Gayol, S. (2000). Sociabilidad en Buenos Aires. Hombres, honor y cafés, 18621910. Ediciones del Signo.

Ginzburg, C.(2004). Tentativas. Prohistoria.

González, J. (2019). El suicidio como problema público en Argentina. Tesis de maestría inédita. Maestría en Epidemiología, Gestión y Políticas de Salud, Universidad Nacional de Lanús, Lanús, Argentina.

Guy, D. (1994). El sexo peligroso, la prostitución legal en Buenos Aires, 18751955. Editorial Sudamericana. 
Guy, D. (2014). Prostitución y suicidio en Buenos Aires, 1880-1900. En D. Barrancos, D. Guy y A. Valobra (Eds.). Moralidades y comportamientos sexuales: Argentina, 1880-2011 (pp. 115-130). Biblos.

Hjelmeland, H. (2010). Cultural Research in Suicidology: Challenges and Opportunities. Suicidology Online, (1), 34-52. http://www.suicidologyonline.com/pdf/SOL-2010-1-34-52.pdf.

Laplaza, F. (1978). El proceso histórico de la Codificación Penal Argentina. Revista de Historia del Derecho Ricardo Levene, (24), 59-92.

Lefebvre, H. (2006). La presencia y la ausencia. Contribución a la teoría de las representaciones. FCE.

Lobato, M. (2000). Los trabajadores en la era del 'progreso. Nueva Historia Argentina. Sudamericana. Tomo V.

Lobato, M. (2007). Historia de las trabajadoras en la Argentina. Edhasa.

Lobato, M. (2011), Te amo, te odio, te quiero: una aproximación a la cultura afectiva de las clases populares en el Río de La Plata, 1880-1930. En G. Chicote y B. Göbel (Eds.). Ideas viajeras y sus objetos: El intercambio entre Alemania y América Austral (pp. 339-349). Bibliotheca IberoAmericana.

Otero, M. (1991). El suicidio en la ciudad de Buenos Aires: su nacimiento como problema social. Tesis de licenciatura inédita. Facultad de Filosofía y Letras, UBA. Buenos Aires, Argentina.

Otero, M. (2004). Le suicide a Buenos Aires: la contribution des médecins à sa <<thématisation>> comme problème social. Canadian Bulletin of Medical History, 32 (2), 41-71.

Owens, C., Owen, G., Belam, J., et al. (2012), Suicide communication events: Lay interpretation of the communication of suicidal ideation and intent. Social Science \& Medicine, 75 (2), 419-428. https://doi.org/10.1016/j.socscimed.2012.02.058.

Pita, V. (2009). La Sociedad de Beneficencia en el manicomio La experiencia de administración y tutela del Hospital de Mujeres Dementes, Buenos Aires, 1852-1890. Tesis de doctorado, Facultad de Filosofía y Letras, Universidad de Buenos Aires, Buenos Aires, Argentina. 
Reguera, A. (2017). Introducción. En A. Reguera (Dir.). Los vínculos que forman redes. Las dimensiones relacionales de lo social y sus articulaciones a escalas diferenciadas. Editorial Teseo.

Rodríguez, F. (1904). Estudios sobre el suicidio en Buenos Aires. La influencia de la edad y del sexo. Archivos de Psiquiatría y Criminología aplicadas a las ciencias afines, año III, enero-febrero.

Scobie, J. (1977). Buenos Aires. Del centro a los barrios. 1870-1910. Ediciones Solar.

Szlajen, F. (2012). Suicidio y Eutanasia: en la filosofía occidental y en lo normativo y filosófico judío. Edición del autor.

Vitenti, L. (2016). Los pueblos indígenas americanos y la práctica del suicidio. Una reseña crítica. Prometeo Libros. 